\title{
Variations in maternal care alter corticosterone and 17beta-estradiol levels, estrous cycle and folliculogenesis and stimulate the expression of estrogen receptors alpha and beta in the ovaries of UCh rats
}

João PA Amorim', Luiz GA Chuffa', Giovana R Teixeira², Leonardo O Mendes', Beatriz A Fioruci', Otávio A Martins ${ }^{2}$, Wílson Mello Júnior ${ }^{2}$, Janete A Anselmo-Franci ${ }^{3}$, Patricia FF Pinheiro ${ }^{2}$, Marcelo Martinez ${ }^{4}$ and Francisco E Martinez ${ }^{2 *}$

\begin{abstract}
Background: Variations in maternal care are associated with neonatal stress, hormonal disturbances and reproductive injuries during adulthood. However, the effects of these variations on sex hormones and steroid receptors during ovary development remain undetermined. This study aimed to investigate whether variations in maternal care are able to influence the hormonal profile, follicular dynamics and expression of AR, ER-alpha and ER-beta in the ovaries of UCh rat offspring.

Methods: Twenty-four adult UCh rats, aged 120 days, were randomly divided into two groups (UChA and UChB) and mated. Maternal care was assessed from birth (day 0) to the 10th postnatal day (PND). In adulthood, twenty adult female rats (UChA and UChB offspring; $n=10$ /group), aged 120 days, were euthanized by decapitation during the morning estrus.
\end{abstract}

Results: UChA females (providing high maternal care) more frequently displayed the behaviors of carrying pups, as well as licking/grooming and arched back nursing cares. Also, mothers providing high care had elevated corticosterone levels. Additionally, offspring receiving low maternal care showed the highest estrous cycle duration, increased corticosterone and 17beta-estradiol levels, overexpression of receptors ER-alpha and ER-beta, increased numbers of primordial, antral and mature follicles and accentuated granulosa cell proliferation.

Conclusions: Our study suggests that low maternal care alters corticosterone and 17beta-estradiol levels, disrupting the estrous cycle and folliculogenesis and differentially regulating the expression of ER-alpha and ERbeta in the ovaries of adult rats.

Keywords: maternal care, sex steroid receptors, corticosterone, E2, ovary

\section{Background}

In mammals, physical and psychological development depends on the relationship established between the mothers and their offspring. Any disturbance during maternal care represents an important factor affecting

\footnotetext{
* Correspondence: martinez@ibb.unesp.br

${ }^{2}$ Department of Anatomy, Bioscience Institute, UNESP - Univ. Estadual

Paulista, Botucatu-SP 18618-970, Brazil

Full list of author information is available at the end of the article
}

the regulation of hypothalamic-pituitary-adrenal axis (HPA) in addition to the pups' care [1]. HPA activation is a central physiological event that is triggered in response to stress. Deficiency in maternal care leads to neonatal injuries, which are subsequently related to disease susceptibility, hormonal imbalances, reproductive damage and social problems in adulthood [2-6].

In adult rats, maternal care includes several integrated elements relating to nutrition and pup care, and these

2011 Amorim et al; licensee BioMed Central Ltd. This is an Open Access article distributed under the terms of the Creative Commons 
elements appear to be spontaneously enacted by primiparous females $[7,8]$. After birth, essential hormones, such as prolactin, oxytocin, estrogen and corticosterone may be associated with maternal interaction [9-11], behavioral and hormonal changes stimulate the female to protect their litters $[12,13]$. However, once the mother-pup relationship is established, the pup's activities signal to the mother to stimulate maternal care. The major stimulus is the presence of pups that attract the attention of the mother with vocalizations, body movements and smell [14-17]. Alterations in maternal care might cause deleterious effects during development, and they seem to be detrimental to female reproduction.

Ovarian steroid hormones, such as estradiol (E2), strongly influence neural circuits that regulate sexual behavior and estrous cycle [18]. The action of E2 and androgens is mediated through estrogen receptors (ER), composed of ER- $\alpha$ and ER- $\beta$ subunits, and androgen receptors (AR), respectively. These receptors belong to a family of steroid nuclear receptors with tissue-specific functions $[19,20]$.

Mothers who offer low maternal care, as well as their daughters, tend to exhibit a reduced level of estrogen receptor $(E R \alpha)$ expression in the brain regions that regulate maternal care and the hypothalamic-pituitarygonadal axis [21-23], but little is known about the influence of maternal care on the expression of ER- $\alpha, E R-\beta$ and $A R$ receptors in the ovarian tissue. Interestingly, this study is the first to report the impact of maternal care on ovarian ER expression. This study also demonstrates that increases in luteinizing hormone $(\mathrm{LH})$ and follicle stimulating hormone (FSH) are necessary for ovulation to occur. The preovulatory LH surge is triggered by LHRH activity, which, in turn, is dependent on increased E2 levels [24-26].

$\mathrm{UCh}$ rats were derived from original Wistar rats and were selected for ethanol consumption at the University of Chile over almost 60 years [27]. These ethanol-preferring rats are considered a special model for understanding of the basis of alcoholism-linked characteristics, such as those found in alcohol-related human diseases.

Despite growing evidence of the consequences of maternal care on offspring development, no study has yet evaluated the effect of maternal care on ovarian activity. Therefore, this study aimed to investigate whether variation of maternal care can alter hormonal levels and estrous-cycle duration, as well as the cell proliferation index, during folliculogenesis and expression of ER- $\alpha, E R-\beta$ and AR in the UCh rat ovary.

\section{Methods}

\section{Animals}

Forty-eight adult male and female UChA and UChB rats, aged 60 days (225-240 g), were obtained from the
Department of Anatomy, Bioscience Institute/Campus of Botucatu, IBB/UNESP - Univ Estadual Paulista. The animals were randomly divided into two groups $(\mathrm{n}=$ 24 /group). All animals were housed in polypropylene cages $(43 \mathrm{~cm} \times 30 \mathrm{~cm} \times 15 \mathrm{~cm})$ with laboratory-grade pine shavings as bedding and maintained under controlled temperature settings $\left(23 \pm 1^{\circ} \mathrm{C}\right)$ and lighting conditions (12-h L, 12-h D photoperiod, lights switched off at $0700 \mathrm{~h}$ ). The animals were handled in accordance with the Ethical Principles in Animal Research adopted by the Brazilian College of Animal Experimentation (COBEA) and approved by the IBB/UNESP Ethical Committee for Animal Research, Protocol 01/08-CEEA.

After UCh rats were individually housed (aged 60 days), they were given a choice between two bottles containing either water or $10 \%(\mathrm{v} / \mathrm{v})$ ethanol ad libitum for 15 days. After this period, 12 animals per group displaying ethanol consumption less than $1.9 \mathrm{~g}$ ethanol $/ \mathrm{kg}$ $\mathrm{BW} /$ day (UChA strain) and higher than $2.0 \mathrm{~g}$ ethanol $/ \mathrm{kg}$ $\mathrm{BW} /$ day (UChB strain; ranging from 4 to $5 \mathrm{~g}$ ethanol/ $\mathrm{kg} /$ day) were selected for the experiment [27]. For this study, the preference ratio associated with ethanol-seeking care was approximately $50 \%$. In addition, to ensure better efficiency and prevent against damage arising from ethanol consumption during pregnancy, the animals were maintained without access to ethanol after preference determination.

\section{Experimental groups}

Male and female rats (120 days old) derived from UChA and UChB lineages were allowed to mate. At night, mature females were housed together with males to encourage copulation. The confirmation of mating was seen in early morning by the presence of sperm on the slides. This finding was designated as day 0 of pregnancy. The rats were monitored once per day, and near the end of pregnancy, rats were monitored twice per day in order to determine time of pup's birth. The time and date of birth was fixed as the postnatal day 0 (PND 0 ), and the sexing and standardization in 8 pups/litter, with proper balance between male and female being ensured in order to avoiding any interference on maternal preference, also occurred at this time. During pregnancy and lactation, the following groups were formed: UChA mothers $(\mathrm{n}=12)$ and UChB mothers $(\mathrm{n}=12)$.

The mothers of both UCh lineages did not receive ethanol during mating, pregnancy or lactation in order to prevent the effects of Fetal Alcohol Syndrome.

\section{Evaluation of maternal care}

Mothers and offspring were housed in individual homecages for evaluation of maternal care. The animals were monitored by one experimenter. Food and water were provided ad libitum. The maternal care was evaluated 
from birth (PND 0) until the 10th postnatal day (PND 10) during 60 minutes of observation four times a day. This observation amounted to $1056 \mathrm{~h}$ of observations. During the 60 minutes observations, each female was observed every 3 minutes for a total of 80 observations/ mother/day. The observations occurred at regular times each day with three periods during the light phase (0800, 1200 and $1600 \mathrm{~h}$ ) and one period during the dark phase $(2000$ h) [5,7]. The measured categories of maternal care were adopted from previous work [28-31]: carrying, licking/grooming, arched-back nursing and licking/grooming, arched-back nursing, passive nursing and contact. No contact with the pups occurred when mothers were engaged in nest building, environmental exploration, self-grooming and feeding.

\section{Estrous cycle analysis}

At 90 days of age, the estrous cycles of female offspring were monitored by colpocytological examination (vaginal smears) every day for 21 consecutive days. Cells detaching from the vaginal epithelium were removed with a pipette (Lab Mate 0.5-10 $\mu \mathrm{L}$, UK). Filter tips containing $10 \mu \mathrm{L} 0.9 \%$ saline were discarded after the vaginal secretions had been transferred to clean slides [32]. Colpocytological examination time was set at $0900 \mathrm{~h}$. Each slide was analyzed under a Zeiss Axiophot II microscope (Carl Zeiss, Germany) at $10 x$ and $25 \times$ magnifications.

\section{Biological sample collection}

At 120 days of age, all UChA and UChB rats in estrous were weighed and euthanized by decapitation. Blood samples were collected and stored at $-80^{\circ} \mathrm{C}$ for further analysis. Ovaries were dissected and weighed using analytical balance (Owalabor) and were fixed by immersion in $10 \%$ buffered formalin.

\section{Follicle counts}

These analyses were performed using 5 - $\mu$ m-thick slices under light microscopy, adopting one section and discarding ten sections in sequence and finally resulting in 12 repetitions/ovary [33]. The primordial, primary, growing (more than two layers until the antral cavity appear), preantral, antral and mature follicles were each counted. All data were analyzed under a Zeiss Axiophot II microscope (Carl Zeiss, Germany) using 20× magnification for primordial and primary follicles and 10X for others.

\section{Immunohistochemistry for Ki-67}

Sections of paraplast-embedded ovaries $(5 \mu \mathrm{m})$ from each offspring were collected on silanized glass slides and pretreated with $2 \mathrm{~N} \mathrm{HCl}$ for $30 \mathrm{~min}$ at $37^{\circ} \mathrm{C}$. Antigen retrieval was achieved by incubating the slides with
$0.1 \%$ trypsin for $15 \mathrm{~min}$ at $37^{\circ} \mathrm{C}$. After washing, the slides were blocked with $3 \%$ hydrogen peroxide in methanol for $20 \mathrm{~min}$ and 3\% bovine serum albumin (BSA) in PBS for $1 \mathrm{~h}$ at room temperature. Next, slides were incubated with monoclonal anti-Rat-Ki-67 antibody (clone MIB-5, Dako, Carpinteria, CA) at a 1:50 dilution in 1\% BSA in PBS and incubated overnight at $4^{\circ} \mathrm{C}$. After washing with PBS, the slides were incubated for $1 \mathrm{~h}$ at room temperature with biotinylated goat antimouse IgG antibody (Santa Cruz Biotechnology, CA) diluted 1:100 in 1\% BSA in PBS. After washing, the sections were incubated with avidin-biotin-peroxidase solution (diluted 1:50) for $45 \mathrm{~min}$ (Elite ABC kit, Vector Laboratory, Burlingame, CA, EUA). Chromogen color development was carried out with 3,3'-diaminobenzidine tetrahydrochloride. Slides were counterstained with Harris's hematoxylin. A negative control was performed by omitting the primary antibody incubation step. The data were analyzed under a Zeiss Axiophot II microscope (Carl Zeiss, Germany). To quantitatively evaluate Ki-67immunostained nuclei (proliferation index), the total number of positive granulosa cells in 10 randomly selected follicles was counted at $40 \times$ magnification for each follicular development stage. The results were expressed as a percentage of total cells counted (number of labeled nuclei $\times 100 /$ total number of cells).

\section{Western blotting analysis and protein quantification}

After euthanasia, the ovaries from UCh offspring were rapidly removed, and tissue samples of $50 \mathrm{mg}$ were immediately frozen in liquid nitrogen and stored at $-80^{\circ}$ C. All tissues were homogenized with RIPA lysis buffer (Pierce Biotechnology, Rockford, IL, USA), using a homogenizer (IKA ${ }^{\circledR}$ T10 basic Ultra, Staufen, Germany). Aliquots of $10 \%$ Triton were added to homogenates, and samples were placed on dry ice for $2 \mathrm{~h}$ for optimal extraction. These suspensions were centrifuged at $21,912 \times \mathrm{g}$ for $20 \mathrm{~min}$ at $4^{\circ} \mathrm{C}$, and the pellet was discarded. Protein concentrations were measured by the Bradford method. Total proteins were dissolved in $1.5 \times$ sample buffer previously described by Laemmli and used for SDS-PAGE (Bio-Rad Laboratories, Hercules, CA, USA). Equal amounts of protein $(70 \mu \mathrm{g})$ were loaded per well onto preformed gradient gels, 4-12\% acrylamide (Amersham Biosciences, Uppsala, Sweden) with a Trisglycine running buffer system for electrophoresis (60 $\mathrm{mA}$ fixed during $2 \mathrm{~h}$ ). After electrophoresis, total proteins were electro-transferred (200 mA fixed by $1 \mathrm{~h} 30$ min) onto $0.2 \mu \mathrm{m}$ nitrocellulose membranes in a Trisglycine-methanol buffer. Prestained standards were used as molecular weight markers. Thereafter, the membranes were blocked with TBS-T solution containing 3\% BSA at room temperature (RT) for $60 \mathrm{~min}$ and subsequently incubated at $4^{\circ} \mathrm{C}$ overnight with rabbit primary 
antibody AR anti-androgen receptor (AR); rabbit clone E115 anti-ER $\alpha$; and rabbit clone 68-4 anti-ER $\beta$ (dilutions of $1: 1000 ; 1: 250 ; 1: 500$ in $1 \%$ BSA, respectively). This step was followed by washing $3 \times 5 \mathrm{~min}$ in TBS-T solution and incubation for $2 \mathrm{~h}$ at RT with rabbit HRPconjugated secondary antibodies (diluted 1:1000 in 1\% BSA; Sigma, St. Louis, MO, USA). After sequential washing with TBS- $\mathrm{T}$, signals were enhanced by mixing $10 \mathrm{~mL}$ PBS, $8 \mu \mathrm{H}_{2} \mathrm{O}_{2}$ and $0.02 \mathrm{~g}$ diaminobenzidine (DAB) as chromogen. Immunoreactive bands of each protein were obtained from blots of six rats per group using image analysis software (NIS-Elements, Advanced Research, Nikon). $\beta$-actin was used as an endogenous control, and all results were expressed as means \pm SEM. Immunoblotting concentrations were represented as optical densitometry values (band intensity/ $\beta$-actin ratio).

\section{Hormone assay}

Blood samples were collected into heparinized tubes from the trunk of decapitated UCh mothers and female offspring after variation of maternal care in the postpartum period. Afterwards, plasma was obtained by centrifugation at $1,200 \times \mathrm{g}$ for $15 \mathrm{~min}$ at $4^{\circ} \mathrm{C}$ and stored at $-20^{\circ} \mathrm{C}$ until assayed by radioimmunoassay (RIA). Plasma samples were assayed for FSH and LH by double-antibody RIA with specific kits provided by the National Institute of Arthritis, Diabetes, Digestive and Kidney Diseases (NIADDK, Baltimore, MD, USA). The FSH primary antibody was anti-rat FSH-S11, and the standard was FSH-RP2. The antiserum for LH was LH-S10 using RP3 as reference. The lower limit of detection for FSH and LH was $0.2 \mathrm{ng} / \mathrm{mL}$ and the intra-assay coefficients of variation were $3 \%$ and $4 \%$, respectively. Plasma concentrations of E2 and P4 were determined using Estradiol and Progesterone Maia kits (Biochem Immunosystems, Serotec, Italy). The lower detection limit and the intra-assay coefficient of variation were, respectively, $7.5 \mathrm{pg} / \mathrm{mL}$ and $2.5 \%$ for E2 and $4.1 \mathrm{ng} / \mathrm{mL}$ and $3.7 \%$ for $\mathrm{P} 4$. Plasma concentrations of corticosterone were determined using specific kits provided by Sigma-Aldrich, Steinheim, Germany. Assay sensitivity was $0.023 \mathrm{ng} / \mathrm{mL}$, and the intra-assay coefficient of variation was $4.5 \%$.

All samples were measured in duplicate and at different dilutions when necessary. In order to prevent interassay variation, all samples were assayed in the same RIA.

\section{Statistical analysis}

The non-parametric Mann-Whitney test was used for general maternal care comparisons. Two Way Repeated Measures ANOVA was performed to evaluate the influence of time (days) along the period of observation (based on two independent factors: time and UCh varieties). Data of follicle counts and percentages were expressed as median followed by quartiles [Q1-Q3]. Student's t-test was applied to other parameters, and the results were expressed as means \pm SEM. Differences were considered significant when $\mathrm{p}<0.05$. The statistical software used was GraphPad Instat version 4 and Sigma Plot version 11.0 for graphic design.

\section{Results}

\section{Maternal care}

UChA females showed greater frequencies of care behaviors than the UChB females, including carrying pups, licking/grooming (L/G) the offspring's anogenital region, arched-back nursing with $L / G$ and arched-back nursing alone. There was no significant difference with regard to passive nursing, although the UChA lactating females presented this care less frequently than did the UChB females. The UChA females displayed additional contact care with their offspring more frequently than did the $\mathrm{UChB}$ females, but this difference was not statistically significant (Table 1).

In addition, maternal care showed considerable during the first 10 days postpartum, with the highest care levels being observed at birth followed by a gradual decrease over time. Two-way repeated measures ANOVA indicated a main effect of both day $\left(\mathrm{F}_{10,24}=5.1, \mathrm{p}<0.001\right)$ and UCh varieties $\left(\mathrm{F}_{1,24}=5.8, \mathrm{p}<0.05\right)$ on the frequency of carrying (Figure 1A). Analysis of licking/ grooming over the first 10 days postpartum indicated a main effect of both day $\left(\mathrm{F}_{10,24}=2.1, \mathrm{p}<0.05\right)$ and UCh varieties $\left(F_{1,24}=15.2, p<0.001\right)$ (Figure $\left.1 B\right)$. Analysis of arched-back nursing with $\mathrm{L} / \mathrm{G}$ indicated of days $\left(\mathrm{F}_{10,24}=\right.$ $1.6, \mathrm{p}=0.12)$ and $\mathrm{UCh}$ varieties $\left(\mathrm{F}_{1,24}=34.8, \mathrm{p}<0.001\right)$ (Figure 1C). Analysis of arched-back nursing over the first 10 days postpartum indicated a main effect of both day $\left(\mathrm{F}_{10,24}=2.5, \mathrm{p}<0.01\right)$ and varieties $\left(\mathrm{F}_{1,24}=99.5, \mathrm{p}\right.$ $<0.001)$, and a significant interaction between day and varieties $\left(\mathrm{F}_{10,24}=2.8, \mathrm{p}<0.01\right)$ (Figure $\left.1 \mathrm{D}\right)$. In frequency of passive nursing the repeated measures ANOVA indicate of both days $\left(\mathrm{F}_{10,24}=7.1, \mathrm{p}<0.001\right)$ and varieties $\left(\mathrm{F}_{1,24}=4.3, \mathrm{p}<0.05\right)$ and a significant

Table 1 Frequency of maternal behaviors during the first 10 days postpartum in UCh lactating females ( $n=12$ /group)

\begin{tabular}{lcc}
\hline Behaviors & UChA Mothers & UChB Mothers \\
\hline Carrying & $11.21 \pm 1.83$ & $4.97 \pm 0.70^{* *}$ \\
Licking/Grooming $(\mathrm{L} / \mathrm{G})$ & $1.99 \pm 0.24$ & $1.01 \pm 0.08^{*}$ \\
Arched-Back Nursing and L/G & $2.30 \pm 0.19$ & $0.98 \pm 0.09^{* * *}$ \\
Arched-Back Nursing & $8.38 \pm 0.17$ & $5.05 \pm 0.40^{* * *}$ \\
Passive Nursing & $1.28 \pm 0.27$ & $1.50 \pm 0.22$ \\
Contact with the pups & $3.67 \pm 0.34$ & $3.17 \pm 0.47$ \\
\hline
\end{tabular}

${ }^{*} p<0.005 ;{ }^{* *} p<0.001 ;{ }^{* * *} p<0.0001$. Mann-Whitney test. Values are expressed as means \pm SEM 
A

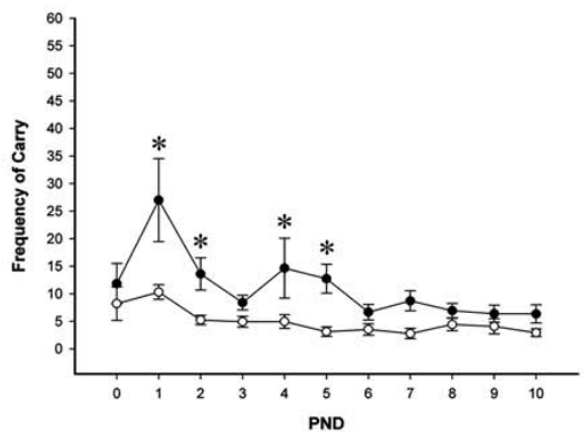

$\mathrm{C}$

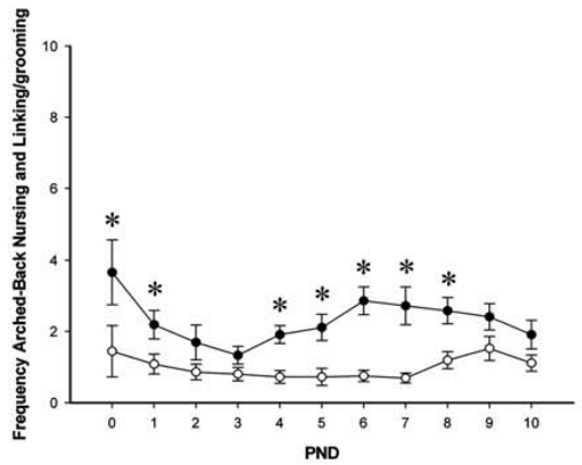

E

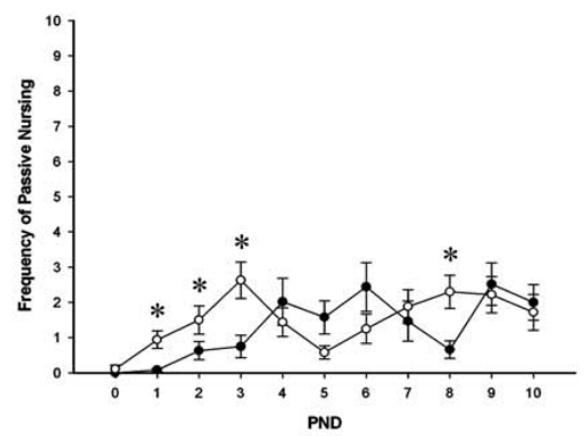

B

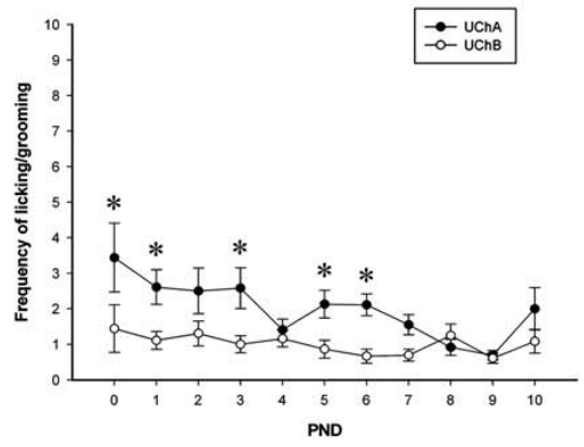

D

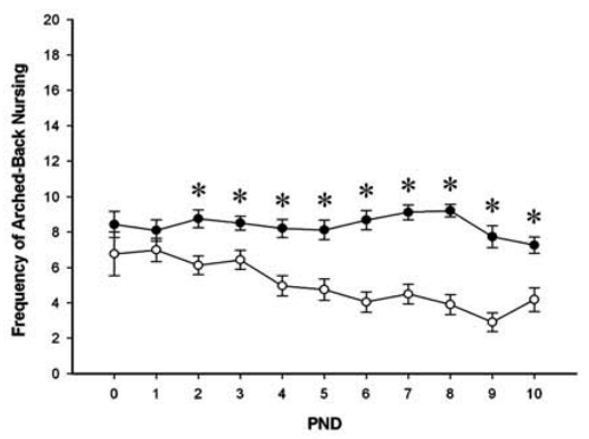

F

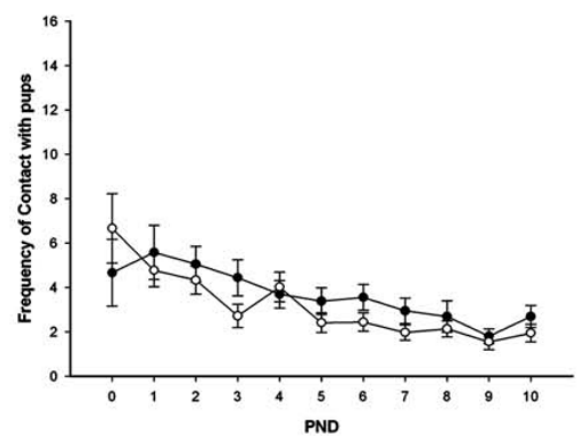

Figure 1 Frequency of maternal care: low care (UChB mothers) and high care (UChA mothers). (A) frequency of carrying; (B) frequency of licking/grooming (L/G); (C) frequency of arched-back nursing and $L / G$; (D) frequency of arched-back nursing; (E) frequency of passive nursing and (F) frequency of contact with pups. Values are expressed as means \pm SEM. UChA and UChB rats ( $n=12 /$ group). Two Way Repeated Measures ANOVA; ${ }^{*} p<0.05$.

interaction between day and strain $\left(\mathrm{F}_{10,24}=2.1, \mathrm{p}<\right.$ 0.05 ) (Figure 1E). Analysis of contact indicated a main effect of day $\left(\mathrm{F}_{10,24}=4.3, \mathrm{p}<0.001\right)$ and $\mathrm{UCh}$ varieties $\left(\mathrm{F}_{1,24}=1.0, \mathrm{p}=0.34\right)$, with females of all varieties decreasing their levels of contact over successive days (Figure 1F). The differences in maternal care between UChA and UChB rats were notably significant during the experiment (Figure 1). 
Analysis of the estrous cycle of female offspring

Female offspring who received low maternal care (UChB rats) exhibited the longest estrous cycle duration with prolonged metestrus stage (3-4 days arrested; Table 2).

\section{Ovary weight and follicles counts of female offspring}

The absolute and relative ovary weights of rats receiving low maternal care (UChB) were significantly higher than those of UChA rats. Also, the UChB rat ovaries had a higher number of primordial, antral and mature follicles, while the primary and growing follicles were predominant in the ovaries of rats receiving high maternal care (Table 3).

\section{Plasma corticosterone and sex hormones}

Mothers providing high maternal care (UChA rats) presented an elevation in corticosterone levels, and conversely, the low maternal care increased both corticosterone and E2 levels in the UChB offspring (Figures 2A, B, E). Plasma LH, FSH and P4 were not significantly different, due to the variations in maternal care during early postnatal life (Figures $2 \mathrm{C}, \mathrm{D}, \mathrm{F}$ ).

\section{Analysis of ovarian AR, ER- $\alpha$, ER- $\beta$ in UCh offspring}

Variations in maternal care resulted in different expression patterns of ovarian sex-steroid receptors. Similarly, ovarian ER- $\alpha$ and ER- $\beta$ were overexpressed in rats that received low maternal care, whereas AR levels did not differ between the groups (Figures 3A, B).

\section{Cell proliferation index (Ki-67) in UCh offspring}

Immunoreactivity for Ki-67 in the granulosa cells of the primary, preantral, antral and mature follicles was significantly higher in animals receiving low maternal care during early postnatal life. In contrast, growing follicles did not show significant differences between the groups (Table 3; Figure 4).

\section{Discussion}

In the rat, variations in maternal care are associated with individual differences during the development of the neuroendocrine and reproductive system, most prominently in the females [34-36]. Evaluation of maternal

Table 2 Duration of estrous cycles in the UCh female offspring ( $n=10 /$ group)

\begin{tabular}{lcc}
\hline Parameters & UChA Offspring & UChB Offspring \\
\hline Estrous cycle duration (days) & $4.00 \pm 0.10$ & $5.86 \pm 0.30^{*}$ \\
Frequency in proestrus (days) & $5.30 \pm 0.15$ & $3.63 \pm 0.15^{*}$ \\
Frequency in estrus (days) & $5.50 \pm 0.16$ & $4.83 \pm 0.56$ \\
Frequency in metestrus (days) & $0.70 \pm 0.26$ & $3.36 \pm 0.43^{*}$ \\
Frequency in diestrus (days) & $9.50 \pm 0.16$ & $9.18 \pm 0.67$ \\
\hline
\end{tabular}

${ }^{*} p<0.05$. Student's $t$-test. Values are expressed as means \pm SEM
Table 3 Body and ovary weights

\begin{tabular}{lcc}
\hline Parameters & UChA Offspring & UChB Offspring \\
\hline Body weight (g) & $233.50 \pm 3.16$ & $240.0 \pm 8.26^{*}$ \\
Absolute ovary weight $(\mathrm{g})$ & $0.059 \pm 0.001$ & $0.074 \pm 0.004^{*}$ \\
Relative ovary weight $(\mathrm{g} / 100 \mathrm{~g})$ & $0.025 \pm 0.001$ & $0.030 \pm 0.001^{*}$ \\
Primordial follicle & $76(59-113)$ & $108(84-133)^{*}$ \\
Primary follicle & $39(14-70)$ & $21.5(15-27)^{*}$ \\
Ki67 index (\%) & $30(20-36)$ & $50(34-75)^{*}$ \\
Growth follicle & $89(49-106)$ & $63.5(46-73)^{*}$ \\
Ki67 index (\%) & $40(20-48)$ & $41(31-58)$ \\
Preantral follicle & $57(28-74)$ & $53.5(41-59)$ \\
Ki67 index (\%) & $41(12-53)$ & $64(42-90)^{*}$ \\
Antral follicle & $58.5(47-74)$ & $72.5(59-86)^{*}$ \\
Ki67 index (\%) & $2.4(2.1-3.5)$ & $8.6(7.3-9.8)^{*}$ \\
Mature follicle & $4.5(4-7)$ & $6(2-11)$ \\
Ki67 index (\%) & $3.7(1.6-10)$ & $15.5(9.09-21.87)^{*}$ \\
\hline
\end{tabular}

Frequency and cell proliferation index of the ovarian follicles in the UCh offspring ( $n=10 /$ group)

Body weight data are expressed as means \pm SEM. Values of frequency and cell proliferation index are expressed as median (Q1 - Q3). Student's $t$-test; ${ }^{*} p$ $<0.05$

care during the first 10 days postpartum revealed significant differences in maternal-infant interaction between the UCh lactating rats. UChA mothers showed higher frequencies of carrying, licking/grooming, arched-back nursing with L/G and arched-back nursing cares. However, the analysis of passive nursing and simple contact with offspring did not show significant differences. Two distinct strategies of maternal care were categorized: first, lactating UChA females offered high levels of mother-offspring contact, exhibited high infant excitement frequency (licking/grooming) and showed devotion to offspring (nutrition and heating); second, UChB mothers showed low levels of excitement and dedication to offspring and high frequencies of maternal rejection. Therefore, female UCh may be high-care (UChA mother) or low-care (UChB mother), similar to other rodent species $[7,37,38]$.

The onset of maternal care in postpartum lactating females reflects hormone concentrations and the densities of hypothalamic receptors that stimulate and prepare the animal, beginning during the prenatal period [39]. Differently from UChB mothers, UChA mothers were more dedicated and busy during the execution of maternal care, evidencing the highest plasma corticosterone levels at the end of lactation. It is well known that mothers treated with moderate concentrations of exogenous corticosterone have increased frequency of licking/grooming and arched-back nursing care activities $[40,41]$. This moderate increase in maternal corticosterone is fundamental to the offspring, as it induces the appropriate development of the aminoacidergic and serotoninergic systems and maturation of hypothalamic- 
A

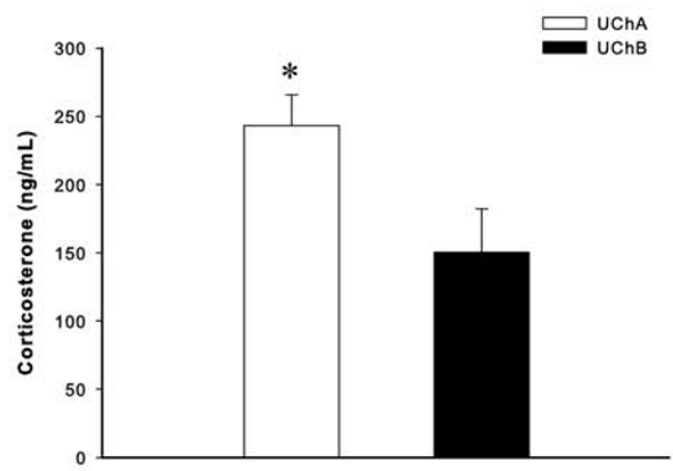

C

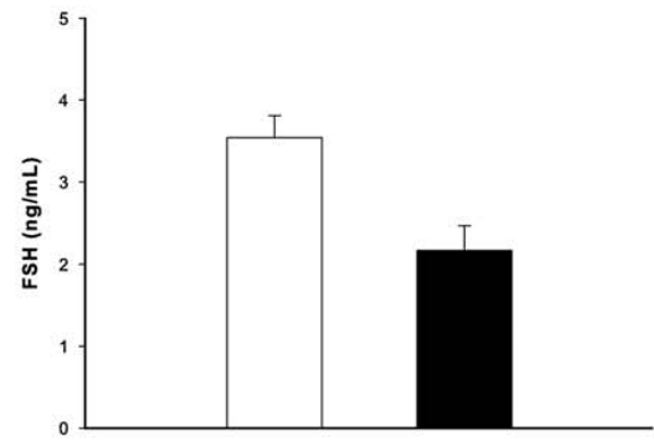

E

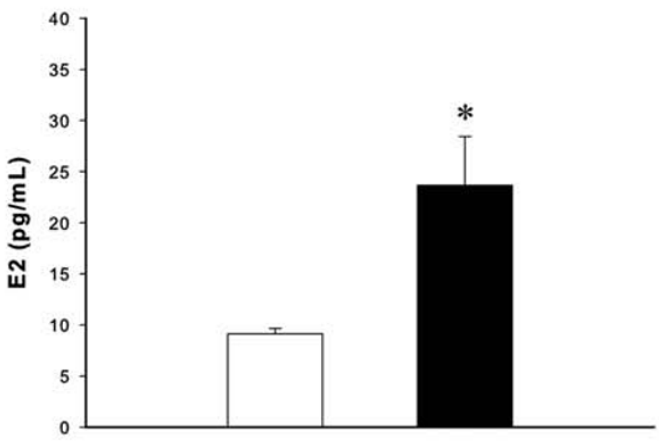

B

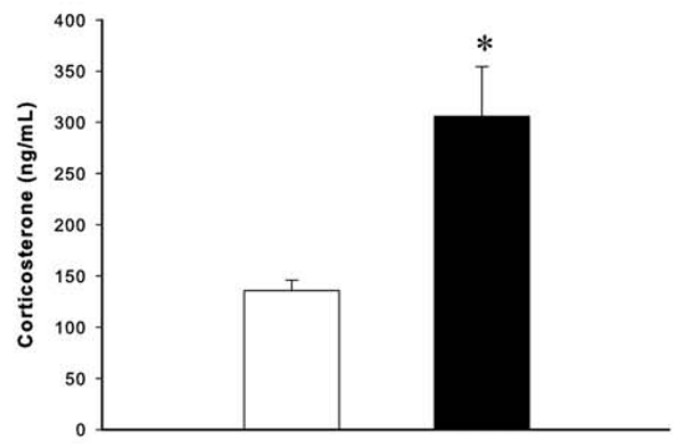

$\mathrm{D}$

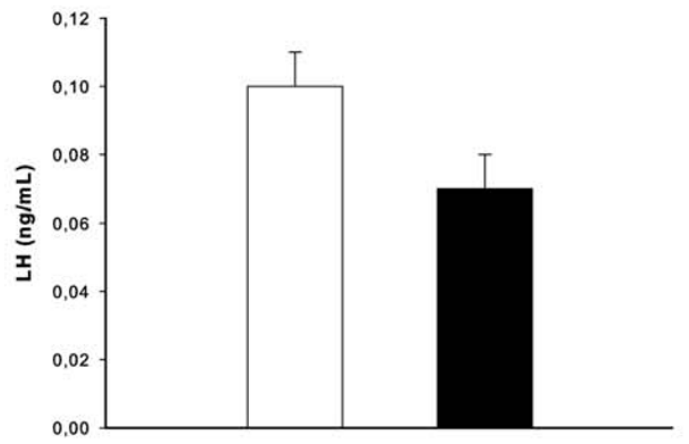

F

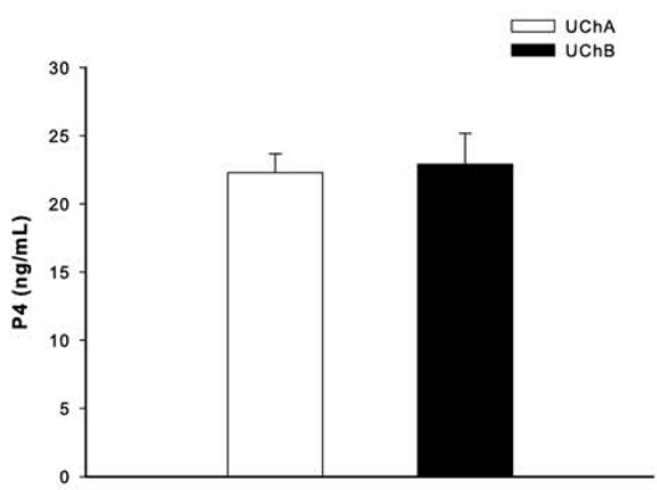

Figure 2 Hormonal profile of UCh mothers and offspring after variation of maternal care in the postpartum period. (A) Plasma corticosterone levels in the UCh mothers $(\mathrm{ng} / \mathrm{mL})$; (B) Plasma corticosterone levels in the UCh offspring ( $\mathrm{ng} / \mathrm{mL})$; (C) Plasma FSH levels in the UCh offspring ( $\mathrm{ng} / \mathrm{mL})$; (D) Plasma LH levels in the UCh offspring $(\mathrm{ng} / \mathrm{mL})$; (E) Plasma E2 levels in the UCh offspring (pg/mL) and (F) Plasma P4 levels in the UCh offspring ( $\mathrm{ng} / \mathrm{mL}$ ). Values are expressed as means \pm SEM. $\mathrm{n}=10$ animals/group. Student's $t$-test; ${ }^{*} p<0.05$. 


\section{(A)}
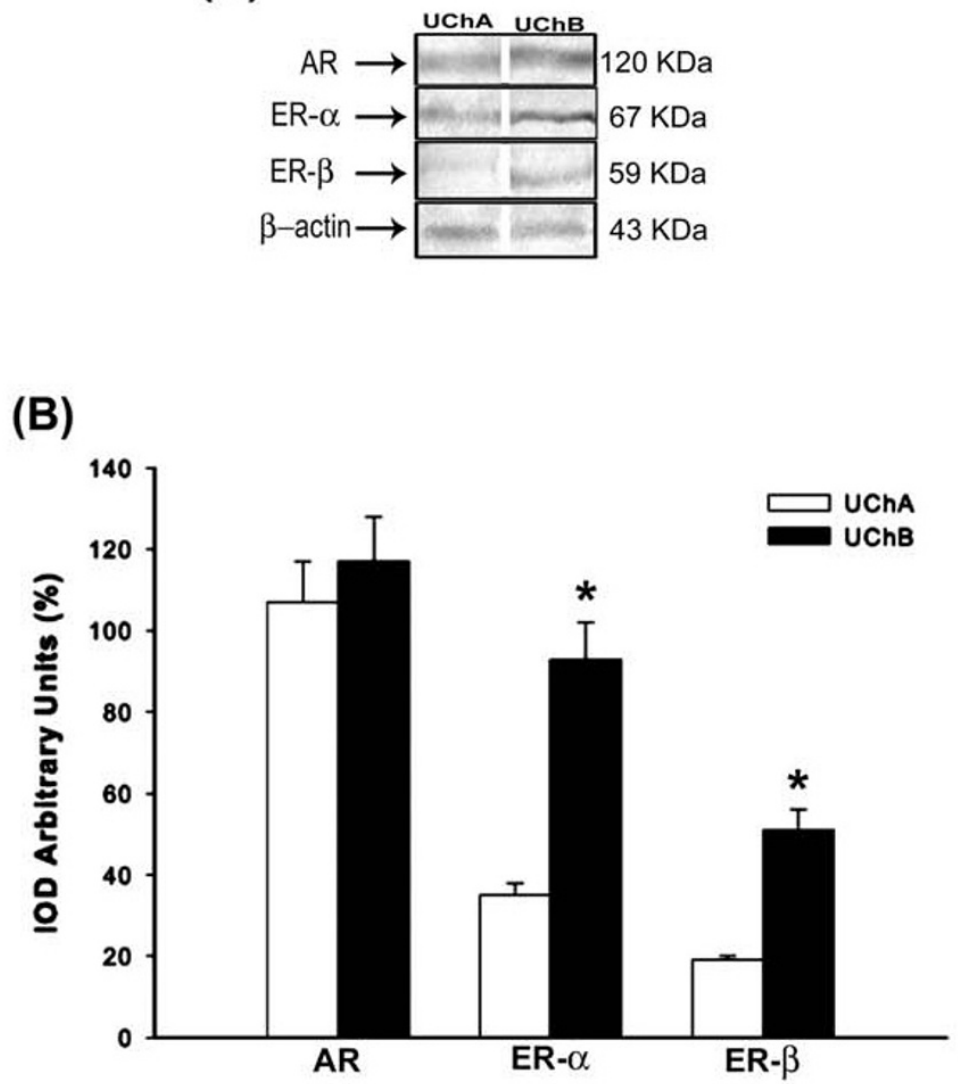

Figure 3 Analysis of ovarian receptors. (A) Representative western blotting analysis of androgen receptor (AR), estrogen receptor subunits (ER$\alpha$ and ER- $\beta$ ) in rat ovaries after variation of maternal care. Indicated concentrations of each total protein $(70 \mu \mathrm{g}$ extracted from a pool of 6 organs/group) were used to detect specific protein expression levels in the blots (upper panel). (B) Densitometry values for AR, ER- $\alpha$ and ER- $\beta$ levels were studied following normalization to the housekeeping gene $\beta$-actin. All results are expressed as means \pm SEM ( $n=6$ animals/group). Student's t-test; ${ }^{*} p<0.05$.

pituitary-adrenal axis, thereby regulating the corticosterone levels in basal conditions and under stress during adulthood [42-44]. Curiously, the UChA offspring that received high maternal care exhibited the lowest concentrations of corticosterone in adulthood. The positive effect of corticosterone on the expression of rat maternal care occurs through its action in the medial preoptic area via E2-ER activation [21]. Female rats receiving low maternal care showed high E2 concentrations, which stimulate mRNA transcription for corticotropin-releasing hormone $(\mathrm{CRH})$ in the hypothalamic paraventricular nucleus (PVN) when mediated by ER- $\alpha$ and ER- $\beta$, thereby increasing the corticosterone secretion $[45,46]$. E2 also exerts a negative regulation on the neurons secreting gonadotropin-releasing hormone (GnRH). Taken together, these results point to the mutual and bidirectional interaction between the hypothalamicpituitary-adrenal and hypothalamic-pituitary-ovarian axis $[47,48]$.
Although FSH levels remained unchanged during the experiment, the UChB offspring had the highest E2 concentrations, as well as overexpression of their receptors. It has already been demonstrated that E2-bound ER induces multiple actions; in particular, ER- $\alpha$ and ER- $\beta$ play different roles during ovarian activity [49]. Interestingly, E2 seems to promote its effects through activation of both ERs, mainly through ER- $\alpha$ in the estrus period. Our data are consistent with the previous report [50] in which ovarian ER- $\alpha$ was upregulated in animals that received low maternal care. To date, nuclear ER- $\alpha$ levels were exclusively documented in extracts from specific brain regions, being significantly elevated in the female offspring of high LG dams $[21,51,36]$.

In UChB rats, the increase in E2 did not induce an $\mathrm{LH}$ surge during ovulation, arresting the estrous cycle in these rats. This result was previously described by [52] in which a prolonged estrous phase was followed by a fall in LH levels but not a lack of ovulation. Evidence 


\section{UChA}
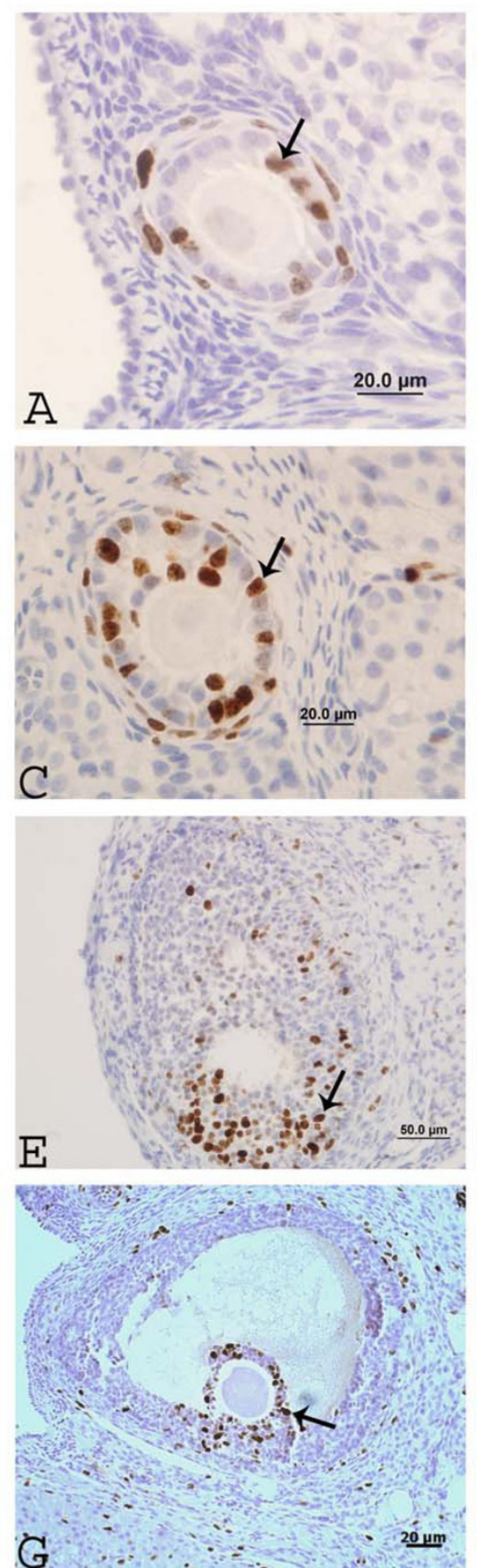

\section{$\mathrm{UChB}$}
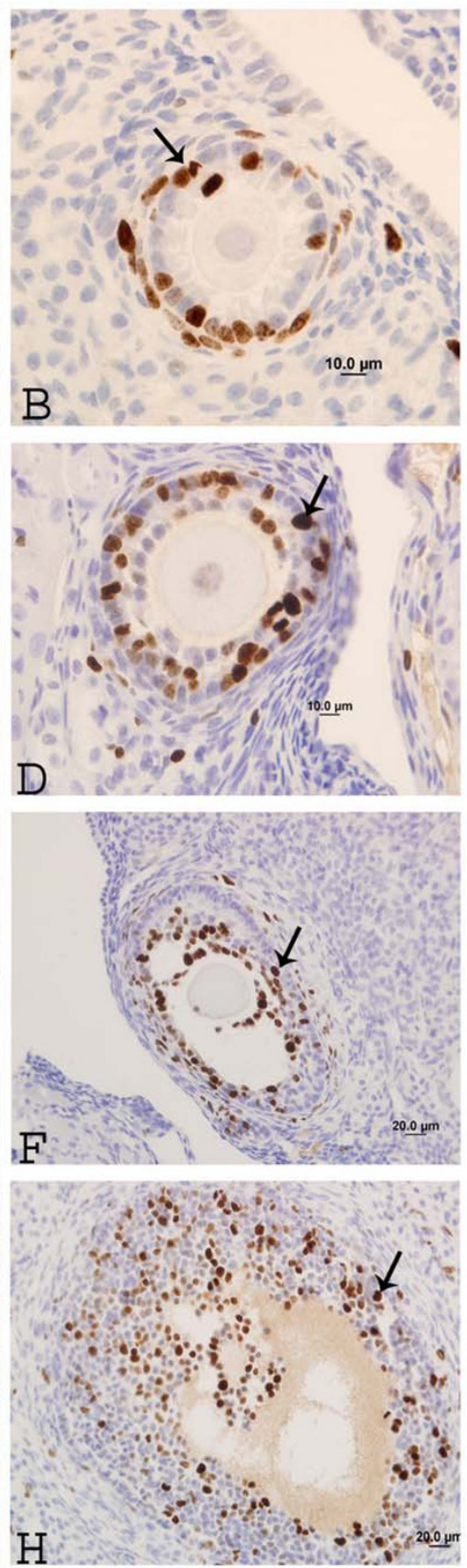

Figure 4 Immunostaining for Ki-67 in different stages of ovarian follicular development in UCh offspring. (A, B) primary follicle; (C, D) growth follicle; $(E, F)$ preantral follicle and $(G, H)$ antral follicle. Arrows show the positive nuclei for Ki-67.

suggests that the LH produced by thecal cells stimulates testosterone synthesis [53], while granulosa cells produce aromatase, an enzyme required for conversion of androgens into estrogens [54]. In our study, it is likely that androgens have been converted to estrogen because variations of stressor agents can modulate aromatase activity [55]. In addition, concentrations of plasma LH and the AR expression did not differ between the 
groups. Ultimately, the ovarian AR was upregulated regardless of the maternal care received. The AR responsiveness could partially explain our findings because low androgen availability leads to upregulation of its receptor. It has been proposed that androgens may act on granulosa cells throughout folliculogenesis by preventing follicular atresia and improving follicle development and maintenance of fertility $[50,56]$. In this regard, the AR-mediated activities are not affected during differential maternal care.

The concentrations of FSH and LH did not vary after maternal care, unlike the concentrations of $\mathrm{E} 2$ in $\mathrm{UChB}$ rats during estrus. Additionally, these rats showed higher ovarian weight and increased number of primordial, antral and mature follicles. It has recently been proposed that the androgen-AR complex is essential to promote the expression of FSH-RH during follicular growth, which stimulates the synthesis of E2 via FSH receptor activation [57]. Furthermore, androgen is responsible for stimulating early follicular growth until preantral development [58]. This regulation through E2 signaling or E2-ER binding was remarkably high in those animals receiving low maternal care, thereby contributing to follicular development. This function appears to be essentially related to primordial and primary follicles [59]. Conversely, the UChA rats exhibited a greater number of primary and growing follicles. These differences in follicular dynamics may be due to changes caused by the specific type and intensity of maternal-infant interaction beside the pattern of response mediated by activation of the HPA on the HPG axis and disturbances of the female sex hormones.

The rats that received low maternal care had higher rates of granulosa cell proliferation at most stages during follicular development. This condition is due to the mitogenic effect produced by E2, probably through an activation pathway initiated by the cyclin D2 in the granulosa cells [60]. In contrast, the UChA offspring showed a reduced granulosa cell proliferation index. It has been recently established that moderate maternal corticosterone levels during the postpartum period are responsible for attenuating cell proliferation in several tissues in adulthood [61].

\section{Conclusion}

We conclude that low maternal care increases the plasma corticosterone and E2 levels, cell proliferation in ovarian follicles and duration of the estrous cycle and also differentially regulates the expression of ER- $\alpha$ and ER- $\beta$ in the ovaries of the offspring during adulthood. Further studies are needed to elucidate the negative effects of low maternal care in the mother-infant interface, especially focusing on the female reproductive system.

\section{Acknowledgements}

We are grateful to Mr. Wanderley Thiago da Silva from Central Biotherium, IBB/UNESP, Botucatu-SP for animal care and Mr. Gelson Rodrigues and Dr. Wagner José Fávaro from the Department of Anatomy, IBB/UNESP for technical assistance. We would like to thank FAPESP (Procs. 07/59355-1 and 08/56229-8) and CAPES specially for providing financial support. This manuscript was edited by American Journal Experts. Certificate Verification Key: CA26-4D9F-4470-E578-0191.

\section{Author details}

'Department of Structural and Cellular Biology, Institute of Biology, Universidade Estadual de Campinas - UNICAMP, Campinas-SP 13083-863, Brazil. ${ }^{2}$ Department of Anatomy, Bioscience Institute, UNESP - Univ. Estadual Paulista, Botucatu-SP 18618-970, Brazil. ${ }^{3}$ Department of Morphology, Stomatology and Physiology, USP - Universidade de São Paulo, Ribeirão Preto-SP 14040-900, Brazil. ${ }^{4}$ Department of Morphology and Pathology, UFSCar - Universidade Federal de São Carlos, São Carlos-SP 13565-905, Brazil.

\section{Authors' contributions}

JPAA, FEM collected and analyzed the data and drafted the manuscript beyond conceiving the main idea of the study. LGAC and GRT: western blotting analysis and substantial interpretation of data. LOM, BAF, MM, OAM, WMJ and PFFP: participated in the acquisition of data, in the design of the study and in the intellectual conception of the study. JAAF participated in all RIA dosages and in interpretation of these data. All authors helped to perform the statistical analyses. All authors read and approved the final version of the manuscript.

\section{Competing interests}

The authors declare that they have no competing interests.

Received: 19 August 2011 Accepted: 22 December 2011

Published: 22 December 2011

\section{References}

1. Walker CD, Deschamps S, Proulx K, Tu M, Salzman C, Woodside B, Lupien S, Gallo-Payet N, Richard D: Mother to infant or infant to mother? Reciprocal regulation of responsiveness to stress in rodents and the implications for humans. J Psychiatry Neurosci 2004, 29:364-382.

2. Liu D, Dioro J, Tannenbaum B, Caldji C, Francis D, Freedman A, Shaema S, Pearson D, Plotsky PM, Meaney MJ: Maternal care, hipocampal glucocorticoid receptors, and hypothalamic-pituitary-adrenal response to stress. Science 1997, 277:1659-1662.

3. Francis DD, Diorio J, Plotsky PM, Meaney MJ: Environmental enrichment reverses the effects of maternal separation on stress reactivity. J Neurosci 2002, 22:7840-7843.

4. Jaworski JN, Francis DD, Brommer CL, Morgan ET, Kuhar MJ: Effects of early maternal separation on ethanol intake, GABA receptor and metabolizing enzymes in adult rats. Psychopharmacology 2005, 181:8-15.

5. Uriarte $R$, Breigeiron MK, Benetti $F$, Rosa XF, Lucion $A B$ : Effects of maternal care on the development, emotionality, and reproductive function in male and female rats. Dev Psychobiol 2007, 49:451-462.

6. Champagne FA, Meaney MJ: Transgenerational effects of social environment on variations in maternal care and behavioral response to novelty. Behav Neurosci 2007, 121:1353-1363.

7. Champagne FA, Francis DD, Mar A, Meaney MJ: Variations in maternal care in the rat as a mediating influence for the effects of environment on development. Physiol Behav 2003, 79:359-371.

8. Numan M: Maternal Behavior.Edited by: Knobil E, Neill, JD. The Physiology of Reproduction Raven Press (New York); , 2 1994:221-302.

9. Macrí S, Mason G, Wurbel H: Dissociation in the effects of neonatal maternal separations on maternal care and the offspring's HPA and fear responses in rats. Eur J Neurosci 2004, 20:1017-1024.

10. Petersen CA, Boccia ML: Oxytocin antagonism alters rat dams' oral grooming and upright posturing over pups. Physiol Behav 2003, 80:233-241.

11. Catalani A, Alemà GS, Cinque C, Zuena AR, Casolini P: Maternal corticosterone effects on hypothalamus-pituitary-adrenal axis regulation and behavior of the offspring in rodents. Neurosci Biobehav Rev 2011, 35:1502-1517. 
12. Michel GF, Tyler AN: Can Knowledge of developmental processes illuminate the evolution of parental care? Dev Psychobiol 2007, 49:33-44

13. Stern JM, Johnson SK: Ventral somatosensory determinants of nursing care in Norway rats. Effects of variations in quality and quality of pup's stimuli. Physiol Behav 1990, 47:993-1011.

14. Rosenblatt JS, Siegel HI, Mayer AD: Progress in the study of maternal behavior in the rat: hormonal, nonhormonal, sensory, and developmental aspects.Edited by: Rosenblatt JS, Hinde RA, Beer C, Busnel MC. Advances in the study of care, Acad. Press, New York; 1979:10:225-311.

15. Rosenblatt JS: Hormonal and nonhormonal regulation of maternal behavior: A theoretical survey. Reprod Nutr Dev 1980, 20:791-800.

16. Polan HJ, Hofer MA: Maternally directed orienting behaviors of newborn rats. Dev Psychobiol 1999, 34:269-279.

17. Coutellier L, Friedrich A, Failing $K$, Wurbel $H$ : Variations in the postnatal environment in mice: Effects on maternal behaviour and behavioura and endocrine responses in the adult offspring. Physiol Behav 2008, 93:395-407.

18. Auger AP: Ligand-independent activation of progestin receptors: relevance for female sexual care. Reproduction 2001, 122:847-855.

19. Koike S, Nii A, Sakai M, Muramatsu M: The steroid binding domain of porcine estrogen receptor. Biochemistry 1987, 5:2563-2568

20. Kuiper GG, Enmark E, Pelto-Huikko M, Nilsson S, Gustafsson JA: Cloning of a novel receptor expressed in rat prostate and ovary. Proc Natl Acad Sci USA 1996, 11:5925-5930.

21. Champagne FA, Weaver ICG, Diorio J, Sharma S, Meaney MJ: Natural variations in maternal care are associated with estrogen receptor alpha expression and estrogen sensitivity in the medial preoptic area. Endocrinology 2003, 144:4720-4724.

22. Erskine MS, Lehmann ML, Cameron NM, Polston EK: Co-regulation of female sexual behavior and pregnancy induction: an exploratory synthesis. Behav Brain Res 2004, 153:295-315.

23. Cameron N, Del Corpo A, Diorio J, McAllister K, Sharma S, Meaney MJ: Maternal programming of sexual behavior and hypothalamic-pituitarygonadal function in the female rat. PLOS One 2008, 21:e2210.

24. Levine JE, Chappell LM, Bauer-Dantoin AC, Besecke LM, Conaghan LA, Legan SJ, Meredith JM, Strobl FJ, Urban JH, Vogelsong KM, Wolfe AM: Neuroendocrine regulation of luteinizing hormone pulse generator in the rat. Recent Prog Horm Res 1991, 47:97-153.

25. Herbison AE: Multimodal influence of estrogen upon gonadotropin releasing hormone neurons. Endocrinol Rev 1998, 19:302-330.

26. Mahesh VB, Brann DW: Regulation of the preovulatory gonadotropin surge by endogenous steroids. Steroids 1998, 63:616-629.

27. Mardones J, Segovia-Riquelme N: Thirty-two years of selection of rats by ethanol preference: UChA and UChB strains. Neurobehav Toxicol Teratol 1983, 5:171-178.

28. Rosenblatt JS: Nonhormonal basis of maternal behavior in the rat. Science 1967, 16:1512-1514

29. Fleming AS, Rosenblatt JS: Maternal behavior in the virgin and lactating rat. J Comp Physiol Psychol 1974, 86:957-972

30. Myers MM, Brunelli SA, Squire JM, Shindeldecker RD, Hofer MA: Maternal behavior of SHR rats and its relationship to offspring blood pressures. Dev Psychobiol 1989, 22:29-53.

31. Pryce $C R$, Bettschen D, Feldon J: Comparison of the effects of early handling and early deprivation on maternal care in the rat. Dev Psychobiol 2001, 38:239-251.

32. Marcondes FK, Bianchi FJ, Tanno AP: Determination of the estrous cycle phases of rats: some helpful considerations. Braz J Biol 2002, 62:609-614.

33. Plowchalk DR, Smith BJ, Mattison DR: Assessment of toxicity to the ovary using follicle quantitation and morphometrics. Methods Toxicol 1993, 3:57-68

34. Cameron NM, Champagne FA, Parent C, Fish EW, Ozaki-Kuroda K, Meaney MJ: The programming of individual differences in defensive responses and reproductive strategies in the rat through variations in maternal care. Neurosci Biobehav Rev 2005, 29:843-865.

35. Cameron NM, Fish EW, Meaney MJ: Maternal influences on the sexual behavior and reproductive success of the female rat. Horm Behav 2008, 54:178-184.

36. Cameron NM, Soehngen E, Meaney MJ: Variation in maternal care influences ventromedial hypothalamus activation in the rat. $J$ Neuroendocrinol 2011, 23:393-400.
37. Caldji C, Tannenbaum B, Sharm S, Francis D, Plotsky PM, Meaney MJ: Maternal care during infancy regulates the development of neural systems mediating the expression of fearfulness in the rat. Proc Natl Acad Sci USA 1998, 95:5335-5340.

38. Meaney MJ, Szyf M: Environmental programming of stress responses through DNA methylation: life at the interface between a dynamic environment and a fixed genome. Dialogues Clin Neurosci 2005, 7:103-123.

39. Rosenblatt JS, Mayer AD, Giordano AL: Hormonal basis during pregnancy for the onset of maternal behaviour in the rat. Psychoneuroendocrinology 1988, 13:29-46.

40. Casolini P, Domenici MR, Cinque C, Alema GS, Chiodi V, Galluzzo M, Musumeci M, Mairesse J, Zuena AR, Matteucci P, Marano G, Maccari S, Nicoletti F, Catalani A: Maternal exposure to low levels of corticosterone during lactation protects the adult offspring against ischemic brain damage. J Neurosci 2007, 27:7041-7046.

41. Graham MD, Rees SL, Steiner M, Fleming AS: The effects of adrenalectomy and corticosterone replacement on maternal memory in postpartum rats. Horm Behav 2006, 49:353-361.

42. Catalani A, Casolini P, Scaccianoce S, Patacchioli FR, Spinozzi P, Angelucci L: Maternal corticosterone during lactation permanently affects brain corticosteroid receptors, stress response and behaviour in rat progeny. Neuroscience 2000, 100:319-325.

43. Leret ML, Peinado V, Suarez LM, Tecedor L, Gamallo A, Gonzalez JC: Role of maternal adrenal glands on the developing serotoninergic and aminoacidergic systems of the postnatal rat brain. Int J Dev Neurosci 2004, 22:87-93.

44. Wilcoxon JS, Redei EE: Maternal glucocorticoid deficit affects hypothalamic-pituitary-adrenal function and behavior of rat offspring Horm Behav 2007, 51:321-327.

45. Lalmansingh AS, Uht RM: Estradiol regulates corticotropin-releasing hormone gene (crh) expression in a rapid and phasic manner that parallels estrogen receptor-alpha and -beta recruitment to a $3^{\prime}, 5^{\prime}$-cyclic adenosine $5^{\prime}$-monophosphate regulatory region of the proximal $\mathrm{crh}$ promoter. Endocrinology 2008, 149:346-357.

46. Miller WJ, Suzuki S, Miller LK, Handa R, Uht RM: Estrogen receptor (ER) beta isoforms rather than ERalpha regulate corticotropin-releasing hormone promoter activity through an alternate pathway. J Neurosci 2004, 24:10628-10635.

47. Yen SSC, Lein A: The apparent paradox of the negative and positive feedback control system on gonadotropin secretion. Am J Obstet Gynecol 1976, 126:942-954

48. Shivers BD, Harlan RE, Morrell Jl, Pfaff DW: Absence of estradiol concentration in cell nuclei of LHRH-immunoreactive neurons. Nature 1983, 304:345-347

49. Zhao L, Watanabe M, Yano T, Yanagisawa J, Nakagawa S, Oishi H, WadaHiraike O, Oda K, Minaguchi T, Yasugi T, Kato S, Taketani Y: Analysis of the status of the novel estrogen receptor a (ERa) coactivator p72 in endometrial cancer and its cross talk with erbB-2 in the transactivation of ERa. Mol Med Report 2008, 1:387-390.

50. Pelletier G, Labrie C, Labrie F: Localization of oestrogen receptor alfa oestrogen beta receptor and androgen receptors in the rat reproductive organs. J Endocrinol 2000, 165:359-370.

51. Champagne FA, Weaver ICG, Diorio J, Dymov S, Szyf M, Meaney JM: Maternal care associated with methylation of the oestrogen receptoralpha $1 \mathrm{~b}$ promoter and oestrogen receptor-alpha expression in the medial preoptic area of female offspring. Endocrinology 2006, 147:2909-2915

52. Chuffa LG, Padovani $C R$, Martinez FE: Ovarian structure and hormonal status of the UChA and UChB adult rats in response to ethanol. Maturitas 2009, 62:21-29.

53. Couse JF, Yates MM, Walker VR, Korach KS: Characterization of the hypothalamic-pituitary-gonadal axis in estrogen receptor (ER) Null mice reveals hypergonadism and endocrine sex reversal in females lacking ERa but not ERß. Mol Endocrinol 2003, 17:1039-1053.

54. Strauss JF, Hsueh AJW: Ovarian hormone synthesis. In Endocrinology. Volume 3.. Fourth edition. Edited by: DeGroot $\sqcup$, Jameson JL. Philadelphia: Saunders Company; 2001:2043-2052.

55. Liu J, Hu P, Qi XR, Meng FT, Kalsbeek A, Zhou JN: Acute restraint stress increases intrahypothalamic oestradiol concentrations in conjunction with increased hypothalamic oestrogen receptor $\beta$ and aromatase mRNA expression in female rats. J Neuroendocrinol 2011, 23:435-443. 
56. Sen A, Hammes SR: Granulosa cell-specific androgen receptors are critical regulators of ovarian development and function. Mol Endocrinol 2010, 24:1393-1403.

57. Nielsen ME, Rasmussen IA, Kristensen SG, Christensen ST, Møllgard K, Wreford Andersen E, Byskov AG, Yding Andersen C: In human granulosa cells from small antral follicles, androgen receptor mRNA and androgen levels in follicular fluid correlate with FSH receptor mRNA. Mol Hum Reprod 2011, 17:63-70.

58. Weil SJ, Vendola K, Zhou J, Adesanya OO, Wang J, Okafor J, Bondy CA: Androgen receptor gene expression in the primate ovary: cellular localization, regulation, and functional correlations. J Clin Endocrinol Metab 1998, 83:2479-2485.

59. Kolibianakis EM, Papanikolaou EG, Fatemi HM, Devroey P: Estrogen and folliculogenesis: is one necessary for the other? Curr Opin Obstet Gynecol 2005, 17:249-253.

60. Robker RL, Richards JS: Hormone-induced proliferation and differentiation of granulosa cells: A coordinated balance of the cell cycle regulators cyclin D2 and p27 ${ }^{\mathrm{kip} 1}$. Mol Endocrinol 1998, 12:924-940.

61. Brummelte S, Galea LA: Chronic corticosterone during pregnancy and postpartum affects maternal care, cell proliferation and depressive-like behavior in the dam. Horm Behav 2010, 58:769-79.

doi:10.1186/1477-7827-9-160

Cite this article as: Amorim et al:: Variations in maternal care alter corticosterone and 17beta-estradiol levels, estrous cycle and folliculogenesis and stimulate the expression of estrogen receptors alpha and beta in the ovaries of UCh rats. Reproductive Biology and Endocrinology 2011 9:160.

\section{Submit your next manuscript to BioMed Central and take full advantage of:}

- Convenient online submission

- Thorough peer review

- No space constraints or color figure charges

- Immediate publication on acceptance

- Inclusion in PubMed, CAS, Scopus and Google Scholar

- Research which is freely available for redistribution

Submit your manuscript at www.biomedcentral.com/submit 